\title{
The Recognition of Intangible Quality Aspects: a topic for the Next Generation
}

\author{
S. A. Liyanage1*, and A. S. K. Warahena2 \\ 1Department of Language Studies \\ 2Department of Manufacturing Technology \\ University of Vocational Technology, Sri Lanka
}

\begin{abstract}
Quality in essence and fineness is essentially an intangibility, even though it is conventionally measured through tangibles which are identified in this discussion as quality peripherals. The peripherals are generally measurable outputs. At times, attempts could be observed to realize quality through what is termed as outcomes, which are exceeding the outputs more qualitatively with in-built characteristics of outputs that are felt by the immediate stake holders of an organization. It is however observable that practicing quality assurance processes are more of 'mechanical' procedures and processes which are forcefully thrust upon individuals though systematic documentary and supervisory approaches. The adherence to the processes has become dutiful requirements rather than willful compliances seen as inner obligations. While it is accepted that the practicing quality assurance processes are the base, it is suggested here that intangible aspects could be recognized and integrated in order to increase the impacts in which all involved become owners, implementers, beneficiaries, and true contributors of quality assurance processes, which could be realized through what is termed here as Quality Reflective
\end{abstract}

Factors (QRF). Redefining the processes and suggesting a conceptualized framework toward achieving this end with special reference to TVET institutes is the ultimatum of this research.

Keywords - Intangible Quality Aspects, Quality Assurance, Quality Reflection Factors, Quality Peripherals

\section{Tangible peripherals in Quality, and the Quality in essence - an introduction}

The Tangible peripherals of Quality (currently being used as the essence of quality practices), is the base or the minimal in assuring quality. There is no argument that the availability of systems that ensure the processes of the stages that are found in Deming Cycle [2] as illustrated in the diagram below Figure 01, the Quality cycle is an interactive four-step problem-solving process, is the base for quality assurance. 
Figure 01: Deming Cycle - tangible peripherals

The Quality cycle includes the sequential phases, namely planning, implementation, evaluation and assessment and review) is primary to any quality assurance attempt. Discussion in this research paper is far beyond the tangible peripherals mentioned in the Deming's.

The existing QA processes and systems are realized through tangible outputs which may be represented through numbers, figures, and records. Quality in essence reaches far, involving or aiming souls of a particular community becoming integral parts of the quality system that seriously consider intangible aspects that are of catalytic importance to realize outcomes, and furthermore the impacts as is illustrated in the diagram below.

\section{The essence of quality - materialistically unseen}

Quality in essence is an intangibility, despite the fact that almost entirety of quality assurance processes focus and are based on tangible outcomes, especially in their measurements. The processes that come to mind in a discussion of quality assurance in global context are ISO series for diverse fields. It could be argued that their main emphasis is to ensure efficiency and effectiveness by systems, and supervisory procedures which compel the relevant 'community' to respond willingly or otherwise. The paper examines how far and how much mind factors which could revolutionize the perspectives of sphere of quality assurance could be relevant in realizing the whole concept.

\section{3. "Outcome" vs. Output" - an inquiry into quality}

When the above Figure 01 is related to an educational context, the output is the number of passed out students. The number is tangible but the total contribution to the immediate society the passed out students make through their holistic behavior could be understood as the outcome, which should only be observed beyond tangible measurements.

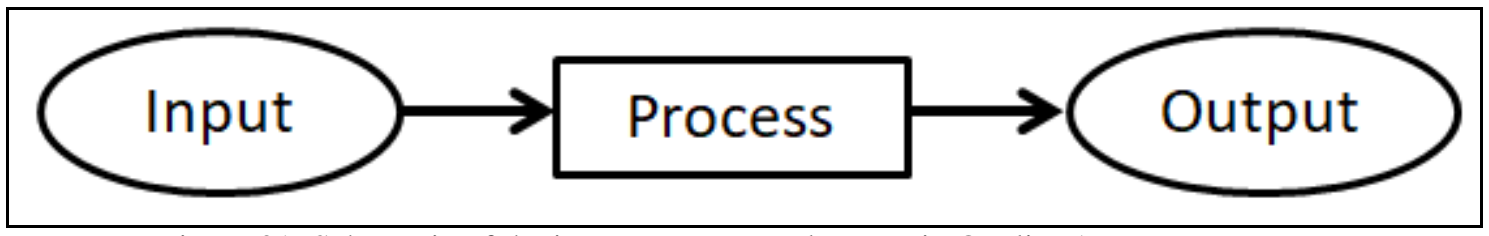

Figure 01: Schematic of the input, Process, and output in Quality Assurance Process

There have been discussions lately about further extended area of output called outcomes. The below figure 02 (a) and (b) are the schematics of the outcome as an extension of output.
Quality assurance is therefore to create a consistent cause to make this (intangible positive values) in the outputs, with which one might identify it as outcome.

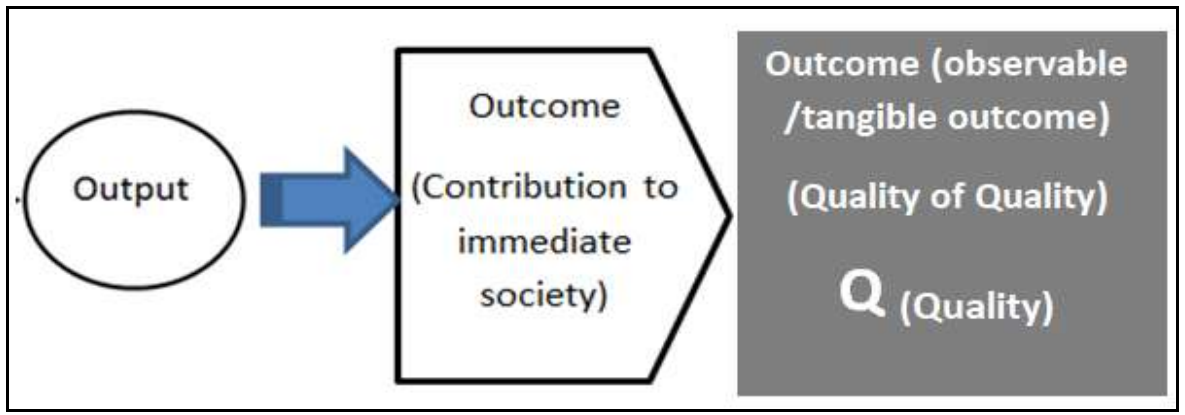

Figure 02 (a): Schematic of the output extended to the Qualitative outcome 


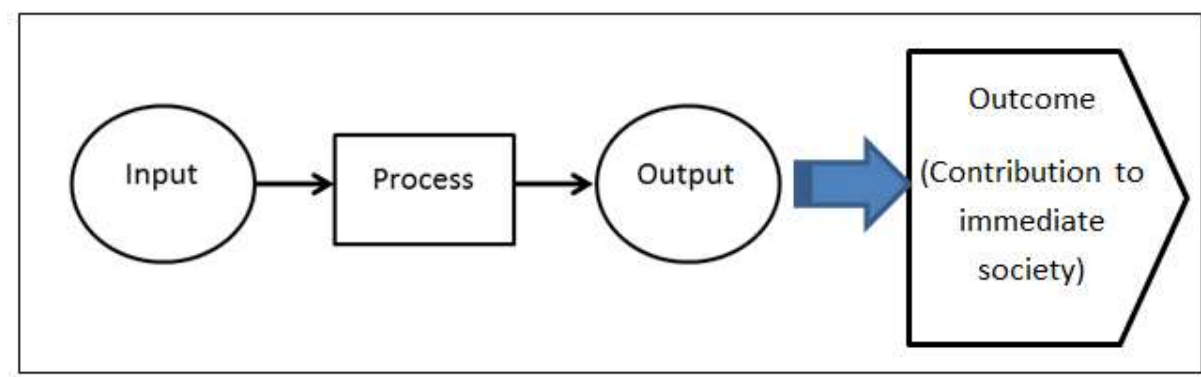

Figure 02 (b): Schematic of the output extended to the Qualitative outcomes

The outcome is 'judged' by the 'value' of the total contribution to the society; this means the numerical value of mere output may have no meaning whatsoever in instances the contribution becomes low or no value. As Sahney, Banwet and Karunes [3] observes "in keeping with the socio-economic and cultural transformation that has placed newer demands on the educational system, in terms of greater responsibility and accountability and increased expectations by stakeholders, the system has been pressurized to shift its focus from one in quantitative expansion to one with emphasis on quality".

What is implied here is that there should be some 'in-built characteristics' in the outputs, for instance, in passed-out students, that make them automatically contribute to immediate society positively. If the focus in this discussion is to narrow down to higher education it can be observed 'under-theorised and under-researched' QA effects in Higher education(Newton, 2013, p. 8), the available methodological options for impact analysis in HE have not been exploited (see, e.g., Stensaker et al., 2011; Suchanek et al., 2012), and important stakeholders, such as students and teachers, have not been ade-quately involved in impact studies (cf. Volkwein et al., 2007, p. 253; Westerheijden et al., 2007, pp. 305, 309). Therefore there is a need for different approach. The idea could be illustrated as follows, with the below figures 03 and 04, together with the recognition of innovative and holistic Quality process for the Quality of Quality. Also considering the outcome as the quality improvements, the above schematic can be evolved as a feedback quality system, as shown below in the Figure 04.

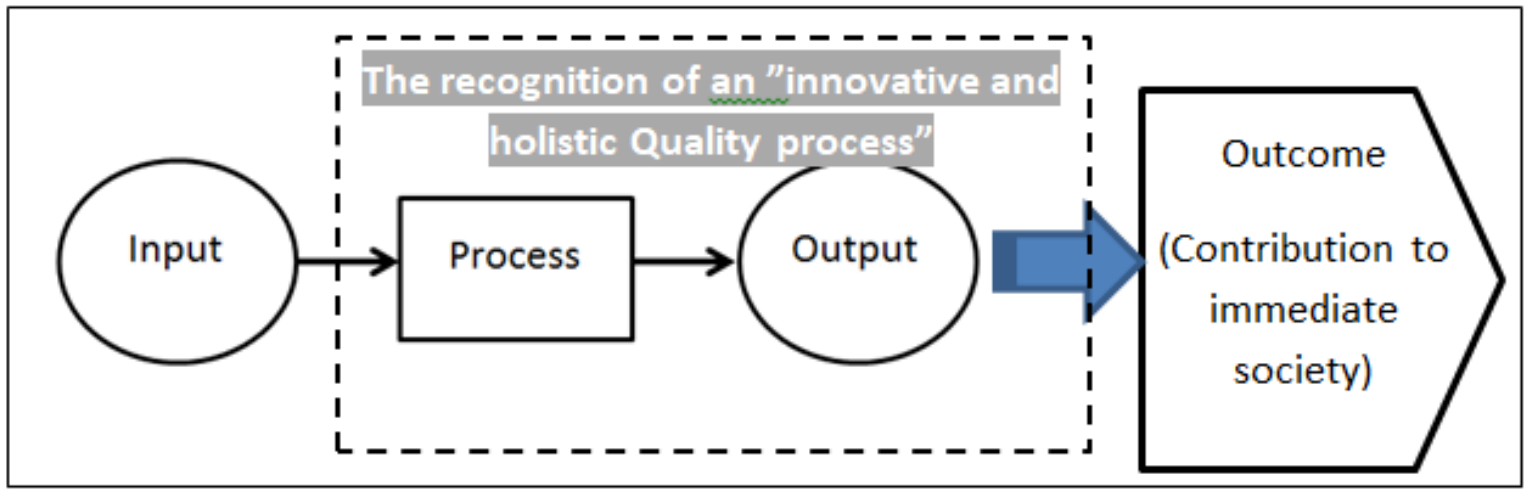

Figure 03: The recognition of an "innovative and holistic Quality process"

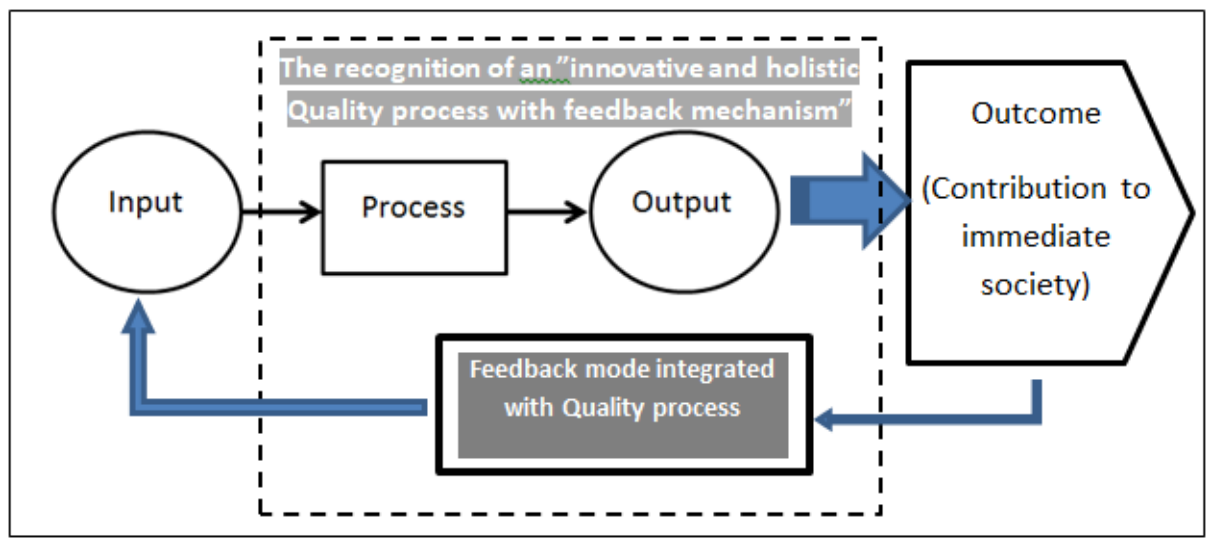

Figure 04: The recognition of feedback integrated "innovative and holistic Quality process" 


\section{Quality Reflection Factors - QRF:}

General belief is that the quality is shown or indicated in measurable and tangible quantities associated with outputs or even outcomes. However, when the outcomes are extended for the holistic levels of socio-economic, peace, and prosperity dimensions, it goes much more beyond technical. And, in such mode of quality, the mental factors and psychologTotal quality management (TQM) describes a management approach to long-term success through customer satisfaction. In a TQM effort, all members of an organization participate in improving processes, products, services, and the culture in which they work. En Anu P. Anil \& K. P (2017)that there exists a positive and significant relationship between Total Quality management Systems (TQM) practices and customer satisfaction level. The study also revealed that knowledge management and customer focus were perceived as the most dominant TQM practices associated with customer satisfaction. What is being investigated through psychological aspects of Quality assurance is a few steps further to ity, as well as ethical dimensions play a huge role. In the judging or evaluation of such integrated and holistic qualitative impacts, the observations must come as the reflections of the social contributions and the impacts seen from the outcomes. We may call this Quality through the reflections, or the Quality Reflection Factors (QRF), as schematically shown in the below Figure 05. The quality (of outcomes) is then defined with QRF.

Depending on the organization, QRFs can be clearly defined and identified. And, in this research study, the below QRFs are suggested for the assurance of quality in general, irrespective of the nature of the organization.

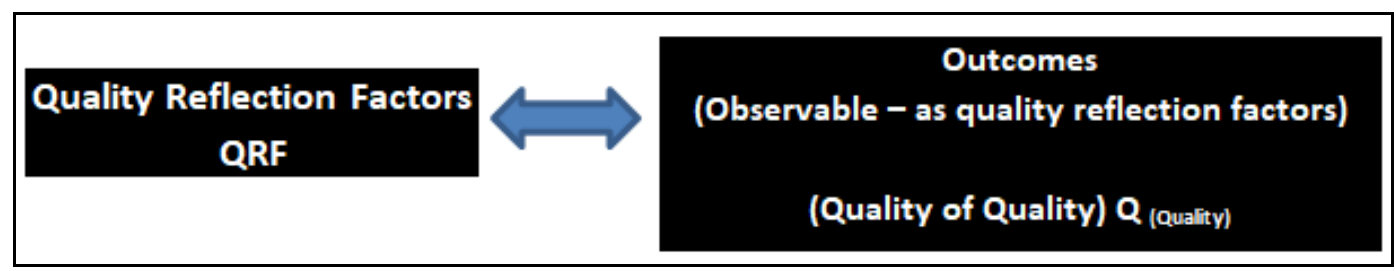

Figure 05: QRFs for judging the outcomes

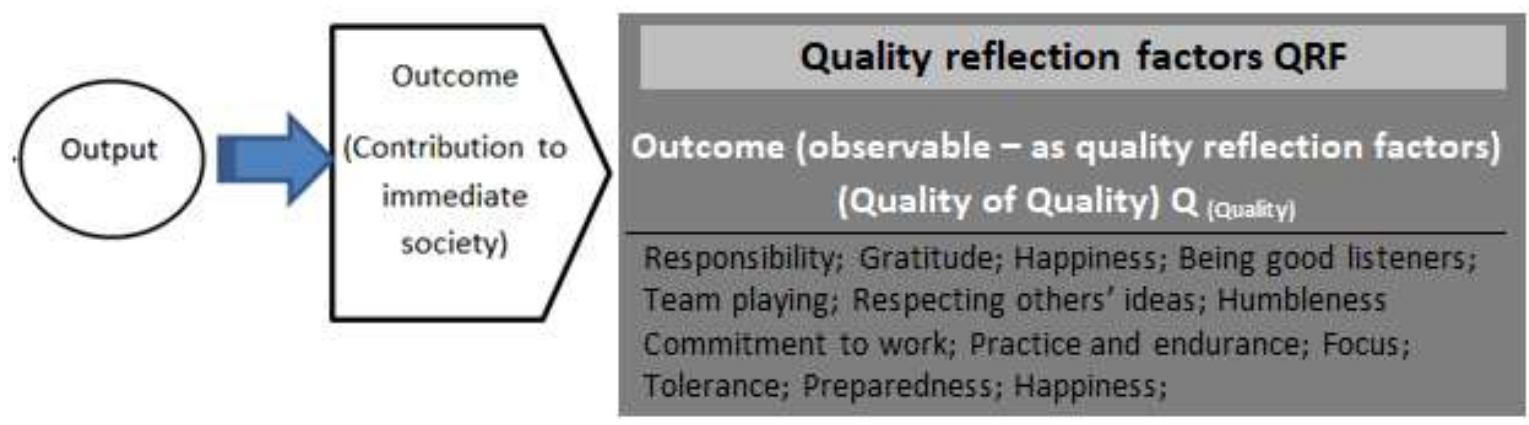

Figure 06: QRFs - an extension of the Quality outcomes

\section{The Intervension}

The intervention by way of a two one-day 'training workshops were conducted in four education and training institutes which belong to TVET in Sri Lanka. The quality assurance and accreditation of study programmes of TVET in Sri Lanka is monitored and regulated by Tertiary and Vocational Education Commission (TVEC). The Quality Management System (QMS) processes were seen as authoritative which required tremendous documentation. The intervention to change the perception was based on a new approach namely Quality Improvement System (QIS), which is a blend of existing QMS and new concept namely Quality is Fun introduced by Boenher (2017). The author of this paper was involved in determining the contents of initial training programmes and a resource person for training the trainers identified as Quality Ambassadors (QAs).

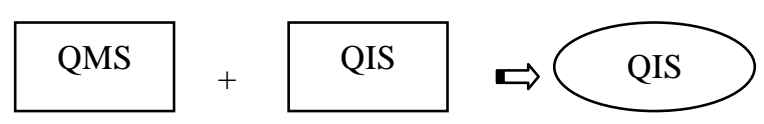


Proc. of the Eighth Intl. Conf. on Advances in Social Science, Management and Human Behaviour - SMHB 2019

Copyright (@) Institute of Research Engineers and Doctors. All rights reserved. ISBN: 978-1-63248-168-9 DOI : 10.15224/978-1-63248-168-9-01

The QMS handles the documentary aspect while the emphasis The blend complements each other to implement a more effective quality assurance in TVET institutes. For instance, among the 15 steps of QIF are (i) forming a Happy Committee and (ii) identifying a Critical Friend which could be identified as very crucial measures for enhancing the Quality Reflection Factors (QRF) within institutes.

In launching the QIS, a two trained QAs will visit an institute and conduct a one-day workshop applying trainee-centred atmosphere in which the QRFs are highlighted. The 15 steps are discussed, individual contracts are signed, happy committee is formed, a Critical Friend is identified, and more importantly, the status of the institute's as far Quality Assurance Continuum (QAC) (- which is a star system) indemnified in QIS is determined and recommended for certification. The next step is to decide on a date for the second visit by the QAs to observe progress and discuss further improvement

The expectation of the process is to inculcate a quality culture within institutes in which the all become owners of the process and all are rewarded for the achievement. Enhancement of quality is now not a duty of a particular officer appointed as was the case in former QMS concept, but behaviour in all from top management to the Office Aide or security officers.

TABLE I. SUMMARY OF THE OBSERVATIONS OF FEEDBACK OF QIS (60 PARTICIPANTS).

The key: NA - not agree, PA-partially agree, A-agree, QAquite agree, $\mathbf{S A}$-strongly agree

\begin{tabular}{|l|l|l|l|l|l|l|}
\hline$\#$ & Statement & NA & PA & A & QA & SA \\
\hline 1 & $\begin{array}{l}\text { I understood that improving } \\
\text { quality in my institute } \\
\text { improves my status as well }\end{array}$ & 00 & 00 & 01 & 10 & 49 \\
\hline 2 & $\begin{array}{l}\text { The QAs contribution in } \\
\text { inculcating a new quality } \\
\text { culture was immense }\end{array}$ & 00 & 00 & 01 & 14 & 45 \\
\hline 3 & $\begin{array}{l}\text { The programme introduced to } \\
\text { look at QMS in a different } \\
\text { angle }\end{array}$ & 00 & 00 & 02 & 08 & 50 \\
\hline 4 & $\begin{array}{l}\text { I believe the Programme is a } \\
\text { firm base for quality } \\
\text { improvement in my institute }\end{array}$ & 00 & 00 & 15 & 10 & 35 \\
\hline 5 & $\begin{array}{l}\text { I sincerely felt I could and } \\
\text { should contribute much to } \\
\text { improve quality in my } \\
\text { institute }\end{array}$ & 00 & 00 & 05 & 17 & 38 \\
\hline 6 & $\begin{array}{l}\text { I felt we should work as a } \\
\text { team to see that our lives and } \\
\text { that of our students are happy }\end{array}$ & 00 & 00 & 00 & 12 & 48 \\
\hline 7 & $\begin{array}{l}\text { I determined to complete my } \\
\text { contract I made with QAs } \\
\text { before the agreed date }\end{array}$ & 00 & 00 & 04 & 14 & 42 \\
\hline
\end{tabular}

\begin{tabular}{|l|l|c|c|c|c|c|}
\hline 8 & $\begin{array}{l}\text { I understood that quality } \\
\text { improvement is not QMR's } \\
\text { or Principal's duty. It is a } \\
\text { responsibility of all of us }\end{array}$ & 00 & 00 & 03 & 17 & 40 \\
\hline 9 & $\begin{array}{l}\text { I would like to be QA and } \\
\text { help other institutes improve } \\
\text { their quality }\end{array}$ & 02 & 07 & 25 & 16 & 10 \\
\hline 10 & $\begin{array}{l}\text { The programme was a } \\
\text { success. }\end{array}$ & & 02 & 05 & 53 \\
\hline
\end{tabular}

Analysis for each statement or calculating correlations between one another are not necessary It is evident that the participants embraced the new approach and how they participated in the one-day intervention could be viewed the visual proof available at request.

The comments made by participants in the feedback strongly justify the impact of the new approach which inculcate a quality culture that ensures the members involve and engage in improving all aspects pertaining to the institute not because compulsion but conviction.

There should be and is close interaction between the QAs and the key contractors which make sure that the initiations made in the one-day programme ends there. With progress, the QAs will arrange the second visit at which point the "assessments" are conducted to recommend higher grades, and the process continues. For instance, for better understanding of this "assessment" a part of the "monitoring rubric for "Happy Committee" is given as annexure (i), and a part of the Checklist for "Critical Friend Visit" (QIS Step 15) as annexure (ii).

\section{The way forward - The conclusion:}

As seen in the figure 04, this research study recognized a comprehensive quality assurance system of the combination of Tangibles (Quality peripherals) and the psychological \& ethical dimensions of QRFs. Even though it is premature to predict the sustainability of the programme but interactions with the participants of limited institutes that the authors have had up to now is promising. It could be concluded that ultimate realization of the true quality, is through continuing this research to realize complete-sustainability through a structured and deliberate inclusion of the intangibles into Quality Assurance processes.

\section{Acknowledgement}

It is with great hounour and gratitude I mention the name of Prof. (Dr.) Markus Boehner, who served the Ministry of Skills Development and Vocational Training, Sri Lanka, as an advisor, attending to mainly to the quality enhancement of the TVET institutes. His "Quality is Fun" concept was embraced 
by the trainers and leaders of TVET who participated in his training programmes; the author was with him from the inception of quality interventions. It is he who inspired me to add this "quality intangibles" or" "Quality Reflection Factors (QRF)" -two terms coined by the authors of this paper- into quality enhancement programmes. I thank Mr. Vajira Perera, and Mr. S U K Rubasinghe (Directors of TVEC, Sri Lanka) and the members of National Coordinating Committee, (QIS) also for opportunity given for continuing working in TVET institutes pertaining to quality enhancement programmes.

\section{References:}

[1] Anu P. Anil \& K. P. Satish Enhancing customer satisfaction through total quality management practices - an empirical examination, Total Quality Management \& Business Excellence,2017, DOI: 10.1080/14783363.2017.1378572

[2]. C.P. Bebko, "Service intangibility and its impact on consumer expectations of service quality", Journal of Services Marketing, 2000, Vol. 14 Issue: 1, pp.9-26.

[3]. A. Chakraborthy,Importance of PDCA cycle for SMEs. SSRG International Journal of Mechanical Engineering (SSRG-IJME),2016 volume 3 Issue 5

[4]. Eight to Late Sense making and Analytics for Organizations https://eight2late.wordpress.com/2012/12/13/what-is-good-and-what-isnot-good-a-project-managers-further-ruminations-on-quality/

[5]. J. Newton, Is quality assurance leading to enhancement?, in Crozier, F. et al. (Eds.), How Does Quality Assurance Make a Difference?, 2013, pp. 8-14 (Brussels, European University Association).

[6]. Stensaker, B., Langfeldt, L., Harvey, L., Huisman, J. \& Westerheijden, D., 2011, An in-depth study on the impact of external quality assurance, Assessment and Evaluation in Higher Education, 36(4), pp. 465-478.

[7] S. Sahney., B.K. Banwet, S.Karunes. "Conceptualizing total quality management in higher education", The TQM Magazine, 2014 Vol. 16 Issue: 2, pp.145-159.

[8] J.Suchanek, M. Pietzonka, R. Künzel, \& T.Futterer, The impact of accreditation on the reform of study programmes inGermany, Higher Education Management and Policy, 2012, 24(1), pp. 1- 24.

[9\. D.F Westerheijden, V. Hulpiau, \& K.Waeyten, From design and implementation to impact of quality assurance: An overview of some studies into what impacts improve-ment, Tertiary Education and Management, 2007,13(4), pp. 295-312.

]10]. J.F. Volkwein., L.R. Lattuca, B.J. Harper \& R.J Domingo, Measuring the impact of professional accreditation on student experiences and learning outcomes, Re-search in Higher Education, 2007, 48(2), pp. 251-282.

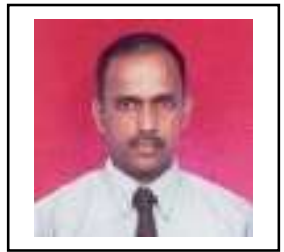

While it is accepted that the practicing (popular) quality assurance processes are the base, it is suggested here that intangible aspects could be recognized and integrated in order to increase the impacts in which all involved become owners, implementers,

beneficiaries, and true contributors of quality assurance processes, which could be realized through what is termed here as Quality Reflective Factors (QRF)

\section{Annexure 1: Part of the Monitoring Rubric for a "Happy Committee" (QIS Step 14)}

\begin{tabular}{|c|c|c|c|c|}
\hline LEVEL & $\begin{array}{c}\text { Beginner } \\
\text { Happy Committee }\end{array}$ & $\begin{array}{c}\text { Aspiring } \\
\text { Happy Committee }\end{array}$ & $\begin{array}{c}\text { Strong } \\
\text { Happy Committee }\end{array}$ & $\begin{array}{c}\text { Excellent } \\
\text { Happy Committee }\end{array}$ \\
\hline $\begin{array}{c}\text { "Happy } \\
\text { Committee" } \\
\text { (HC) }\end{array}$ & $\begin{array}{l}\text { - accomplishes a few of the } \\
\text { obligatory tasks (such as } \\
\text { looking into maintenance, } \\
\text { job satisfaction, social } \\
\text { events, further ed and } \\
\text { promotion etc.) } \\
\text { - meets several times, but not } \\
\text { regularly } \\
\text { - sometimes talks to } \\
\text { colleagues about their well- } \\
\text { being } \\
\text { - has once collected center- } \\
\text { wide data about staff's well- } \\
\text { being }\end{array}$ & $\begin{array}{l}\text { - accomplishes several of the } \\
\text { obligatory tasks } \\
\text { - meets typically at least } \\
\text { once a month } \\
\text { - talks to colleagues about } \\
\text { their well-being } \\
\text { - collects center-wide data } \\
\text { about staff's well-being } \\
\text { more often } \\
\text { - usually talks to Quality } \\
\text { Steering Committee (QSC) } \\
\text { - typically takes up problems } \\
\text { of staff members, if known, } \\
\text { and discusses them with }\end{array}$ & $\begin{array}{l}\text { - accomplishes many of the } \\
\text { obligatory tasks } \\
\text { - meets at least once a } \\
\text { month, often on the same } \\
\text { day according to a fixed } \\
\text { schedule } \\
\text { - steadily talks to } \\
\text { colleagues about their } \\
\text { well-being according to } \\
\text { an established procedure } \\
\text { - regularly collects center- } \\
\text { wide data about staff's } \\
\text { well-being, following an } \\
\text { established collection }\end{array}$ & $\begin{array}{l}\text { - } \text { accomplishes most of the obligatory } \\
\text { tasks } \\
\text { - meets consistently according to a } \\
\text { pre-arranged schedule at least once a } \\
\text { month } \\
\text { - constantly talks to colleagues about } \\
\text { their well-beings according to a well- } \\
\text { ingrained procedure } \\
\text { - consistently collects center-wide data } \\
\text { about staff's well-being, following } \\
\text { scientific collection rigor } \\
\text { - always talks to QSC, frequently } \\
\text { participates in QSC meetings } \\
\text { - constantly strives to discover }\end{array}$ \\
\hline
\end{tabular}


Proc. of the Eighth Intl. Conf. on Advances in Social Science, Management and Human Behaviour - SMHB 2019

Copyright $($ Institute of Research Engineers and Doctors. All rights reserved. ISBN: 978-1-63248-168-9 DOI : 10.15224/978-1-63248-168-9-01

\begin{tabular}{|c|c|c|c|c|}
\hline in operation & $\begin{array}{l}\text { - has already floated ideas } \\
\text { about staff events } \\
\text { - } \text { sometimes talks to Quality } \\
\text { Steering Committee } \\
\text { - has taken up the problem of } \\
\text { at least one staff member } \\
\text { and discussed with } \\
\text { management } \\
\text { - cooperates with management } \\
\text { occasionally } \\
\text { - has implemented at least one } \\
\text { quality (unconventional) } \\
\text { measure concerning more } \\
\text { happiness at work } \\
\text { - all staff is aware of BHC's } \\
\text { existence } \\
\text { HC }\end{array}$ & $\begin{array}{l}\text { management } \\
\text { - generally cooperates with } \\
\text { management } \\
\text { - has already implemented a } \\
\text { few quality measures } \\
\text { concerning more happiness } \\
\text { at work } \\
\text { - all staff is aware of BHC's } \\
\text { existence and gives input to } \\
\text { its work } \\
\text { - there is a board for BHC's } \\
\text { announcements and } \\
\text { obviously in use (physical } \\
\text { of digital) } \\
\text { - there is a BHC-operated }\end{array}$ & $\begin{array}{l}\text { scheme } \\
\text { - frequently talks to QSC } \\
\text { and is invited to OSC } \\
\text { meetings } \\
\text { - often actively tries to find } \\
\text { out about problems of } \\
\text { staff members, takes them } \\
\text { up and discusses them } \\
\text { with management } \\
\text { - frequently cooperates } \\
\text { with management } \\
\text { - often implements quality } \\
\text { (sometimes } \\
\text { unconventional) measures } \\
\text { concerning more } \\
\text { happiness at work }\end{array}$ & $\begin{array}{l}\text { problems of staff members, standing } \\
\text { in for them and tries to find solutions } \\
\text { with management } \\
\text { - consistently cooperates with } \\
\text { management, meeting them } \\
\text { according to a schedule } \\
\text { - steadily implements (also } \\
\text { unconventional) quality measures } \\
\text { concerning more happiness at work } \\
\text { - all staff is happy about BHC's } \\
\text { existence, supports and interacts } \\
\text { actively } \\
\text { - BHC's board is a transparency } \\
\text { platform for the entire center } \\
\text { (physical of digital) }\end{array}$ \\
\hline
\end{tabular}

\section{Annexure (ii): Part of the Checklist for "Critical Friend Visit" (QIS Step 15)}

\section{I, as a critical friend: (Please tick off the boxes!)}

(1) I checked premises and all buildings for shortcomings and chances to improve

YES

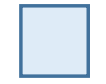

NO

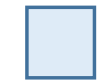

These are my findings and suggestions:
PARTLY

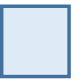

(2) I checked all classrooms and workshops for teaching material and maintenance of machinery as well adequacy of equipment:

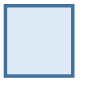

YES
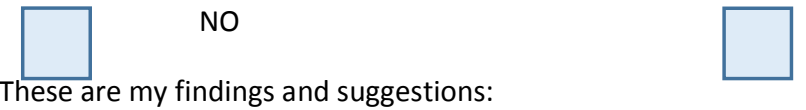

PARTLY

(3) I talked in depth (at least 15 minutes) to at least 8 members of staff from all levels of hierarchy about their perceptions of quality at work, what goes right and wrong and how they feel as well about what they think about leadership:

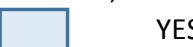

No

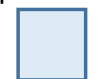

PARTLY

(4) I discussed with at least 15 students of the institute (at least 5 minutes) how they think administration and teaching is like, how they are supported by their teachers, what they think about leadership, how they like the premises and rooms as well as equipment, what they think about food and washrooms and how they feel in general:

YES

NO

PARTLY

These are my findings and suggestions:

(5) I had a discussion with the Quality Committee on quality issues and their work in the last year first thing in the morning (at least 20 minutes) and a discussion with the Happy Committee (or two random members of staff) how happy employees are at this institute, and why, (at least 10 minutes), as a second thing in the morning:

NO

PARTLY
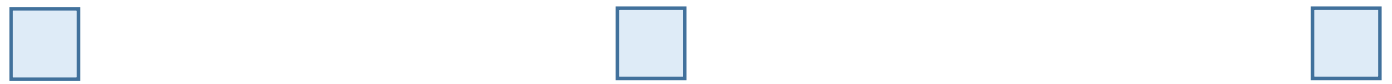